\title{
Targeted Nanostructured Lipid Carrier for Brain Delivery of Artemisinin: Design, Preparation, Characterization, Optimization and Cell Toxicity
}

\author{
Jaber Emami ${ }^{1}$, Hessam Yousefian $^{1}$, and Hojjat Sadeghi ${ }^{2}$ \\ ${ }^{1}$ Department of Pharmaceutics and Isfahan Pharmaceutical Research Center, School of Pharmacy and Pharmaceutical \\ Sciences, Isfahan University of Medical Sciences, Isfahan, I.R. Iran. ${ }^{2}$ Department of Medicinal Chemistry and Isfahan \\ Pharmaceutical Research Center, School of Pharmacy and Pharmaceutical Sciences, Isfahan University of Medical Sciences, \\ Isfahan, I.R. Iran.
}

Received, August 8, 2018; Accepted, September 21, 2018; Published, September 24, 2018.

\begin{abstract}
In the present study, a transferrin-conjugated nanostructured lipid carrier (TF-NLCs) for brain delivery of artemisinin (ART) was developed. ART-loaded NLCs (ART-NLCs) were prepared using solvent evaporation method and the impact of various formulation or process variables on the responses were assessed using a Taguchi design. Optimized ART-NLC was then coupled with transferrin as targeting ligand and its in vitro cytotoxicity was investigated against U-87MG brain cancer cell line. As a result, the following values are suggested by the software to prepare the optimized formulation: $20 \mathrm{mg}$ Compritol ${ }^{\circledR}, 0.25 \%$ Tween $80,5 \mathrm{mg}$ oleic acid, $2.5 \mathrm{~mL}$ dichloromethane and $4 \mathrm{~min}$ sonication. Mean particle size (PS), zeta potential (ZP), polydispersity index (PDI), entrapment efficiency (EE), mean release time (MRT) of adopted formulation were confirmed to be $145 \pm 12.5 \mathrm{~nm}, 24.3 \pm 1.5 \mathrm{mV}, 0.513 \pm 0.021,82.3 \pm 7.3 \%$ and $24.0 \pm 1.1 \mathrm{~h}$, respectively. Following conjugation of optimized ART-NLCs with TF, PS and MRT were increased, while ZP, and EE were decreased significantly. TF-ART-NLCs showed higher cytotoxic activity compared to non-targeted NLCs and free drug. These results indicated that the TF-ART-NLCs could potentially be exploited as a delivery system for anticancer and antimalarial drug ART in brain tumors and malaria.
\end{abstract}

\section{INTRODUCTION}

Brain cancers are still a significant health problem worldwide amongst which malignant glioma are the most common primary brain tumor. The median survival time for patients with glioma is ranging between 3 and 16 months $(1,2)$. Due to rapid proliferation and tendency of tumor cells to infiltrate into the normal brain tissue and because of wide distribution of the cancerous cells at the time of diagnosis (3) makes the complete tumor resection impossible (4). Therefore, chemotherapy seems essential as the supporting treatment of malignant glioma.

Artemisinin (ART), a natural molecule isolated from Artemisia annua, is a sesquiterpene trioxane lactone with an endoperoxide bridge that is essential for its various activities. ART, which is commonly used in malaria therapy, has shown potent anticancer activity both in vitro and in vivo in sensitive and drug- or radiation-resistant cell lines (5-7), but experience in human cancer is scarce.

The anticancer activity of ART is mediated via oxidative stress responses. The endoperoxide bond in the ART molecule is cleaved by ferrous iron $\left(\mathrm{Fe}^{2+}\right)$ generating cytotoxic carbon-centered free radicals, which are highly potent alkylating agents. Other mechanisms of anticancer activity of ART are protein alkylation, angiogenesis reduction, apoptosis induction, oncogenes inhibition and tumor suppressor genes induction ( 8). The cytotoxic effect of ART is specific to cancer cells because most cancer cells over-express transferrin receptors on their surface for iron uptake and have higher iron influx than normal cells. Most normal cells express nearly undetectable levels of transferrin receptors (9). The molecular basis of the anticancer effects of ART and precise activation approach are not fully described. ART can regulate key factors such as nuclear factor-kappa B, surviving, NOXA, hypoxiainducible factor-1alpha and BMI-1, involving multiple pathways that may affect drug resistance, drug reaction, drug interfaces and associated factors upon normal cells (10).

Corresponding Author: Jaber Emami, Department of Pharmaceutics and Isfahan Pharmaceutical Research Center, School of Pharmacy and Pharmaceutical Sciences, Isfahan University of Medical Sciences, Isfahan, I.R. Iran, E-mail: emami@pharm.mui.ac.ir 
Because of its strong cytotoxic activity, ART has exhibited antitumor activity against melanoma, breast, ovarian, prostate, central nervous system, and renal cancer cell lines $(11,12)$. It has been suggested that ART may be a therapeutic alternative in aggressive cancers with fast dissemination without developing drug resistance $(8,10)$.

ART also show synergism with other antitumor drugs with no increased toxicity to normal cells (8). Importantly, artemisinin is one of the very few drugs that have been widely used as antimalarial but has no significant side effects (13) or clinical resistance, although tolerance has been reported (14). Naturally, artemisinin has low solubility in water or oil, poor bioavailability $(30 \%)$ due to high first pass metabolism, and a short half-life of about $2.5 \mathrm{~h}$ in vivo. Artemisinin and all its derivatives metabolize to form the dihydro-form of artemisinin and artenimol. Artemisinin appears to be a potent autoinducer of drug metabolism in rats and humans. Thus, during multiple administrations, the exposure of the drug will not be constant over time (15).

Despite potential efficacy, the very low water solubility, non-selective targeting towards cancer cells and poor penetration and delivery across the blood brain barrier limits its applications in brain cancers (16). An increased site specificity and internalization can improve the efficacy of treatment and decrease the possibility of side effects. In order to deliver drugs with poor blood brain barrier permeability, some invasive approaches such as transient opening of the blood brain barrier by arterial injection of hyperosmolar agents including mannitol and arabinose have been investigated but the risk of infection and neurosurgical cost questions its cost effectiveness. Incorporation of ART in micro- or nano-particles can potentially overcome the aforementioned limitations.

Numerous drug delivery systems including PCL-PEG-PCL micelles (17), biodegradable mPEG-PCL core-shell micelles (18), nanoliposomes (19), chitosan, gelatin, and alginate nanocapsules (20), pegylated nanoliposome (21), and ordered mesoporous SBA-15 particles (22), have been so far studied and evaluated to improve solubility, bioavailability or stability of ART for its parenteral delivery into cancer cells. Nevertheless, none of these delivery systems is designed to selectively promote ART transport and its delivery to the brain tumors via blood brain barrier.

Ligand-anchored drug delivery systems have presented great potentials in achieving better sitespecific drug delivery. A very recent approach is the conjugation of targeting ligands to nanoparticles, which can carry the particles through blood brain barrier. This approach is based on the fact that the brain endothelial cells of the blood brain barrier as well as the glioma cells overexpress certain cellsurface receptors like transferrin receptor (23). Transferrin mediated drug delivery systems including transferrin-conjugated solid lipid nanoparticles (SLNs) (24), PLGA nanoparticles (25), gold nanoparticles (26), human serum albumin nanoparticles (27), magnetic nanoparticles (28), and nanostructured lipid carriers (NLCs) (23) have been developed and studied in recent years for targeted brain delivery of various drugs.

The potential advantages of SLN as a drug carrier system over other colloidal delivery systems including high lipophilicity, fine particle size, biocompatibility, sterility, scale up and protection of incorporated active ingredients against chemical degradation (29) make these particles appropriate carrier for brain drug delivery. However, low drug loading (DL) capacity, drug expulsion during storage due to the crystallization of lipid matrix or lipid polymorphism, less flexibility to release drug with desired pattern are some potential limitations with SLNs.

To overcome these drawbacks, nanostructured lipid carriers (NLCs) that composed of a combination of solid lipids and liquid lipids have been developed as lipid particle new generation and innovative carrier systems (30).

In the current study, for the first time, we have developed ART-loaded transferrin- conjugated NLCs for targeted delivery of the drug towards brain cancer cells. NLCs were prepared by solvent evaporation method using cholesterol (a solid lipid), oleic acid (a liquid lipid) and stearylamine as transferrin conjugating lipid having amino group. Transferrin was coupled by its carboxylic group to the amino group of stearylamine presenting on the surface of artemisinin-loaded NLCs (ART-NLCs). A Taguchi design with seven factors at two levels was used to optimize the formulation. Physical properties of these formulations were evaluated. Optimized formulation was conjugated with transferrin and coupling efficiency of NLCs was evaluated. Cell toxicity of targeted formulation was evaluated on U87MG cells using MTT assay. U87, a human glioblastoma cell, is a major type of malignant brain cancer cell overexpressing transferrin receptor (TfR) making it excellent candidate for targeted therapeutics. Thus, U87 was selected for the cellular uptake assay (31). 


\section{METHODS AND MATERIALS}

\section{MATERIALS}

Artemisinin, cholesterol, Compritol ${ }^{\circledR}$, poloxamer 188, cephadex G-50, N-ethylcarbodiimide hydrochloride (EDC), anhydride dimethyl sulfoxide (DMSO), 3-(4,5-dimethylthiazol-2-yl)-2,5diphenyltetrazolium bromide (MTT) were purchased from Sigma-Aldrich (St. Louis, MO). Stearylamine, soy lecithin, oleic acid, tween 80 , ethanol, potassium dihydrogen phosphate, sodium hydroxide, dichloromethane and transferrin were supplied by Merck (Darmstadt, Germany). Fetal bovine serum (FBS) and penicillin-streptomycin were obtained from (Biosera, Ringmer, UK). Phosphate-buffered saline (PBS) and trypsin-EDTA were procured from Bio-idea (Tehran, Iran). Human primary glioblastoma cell line (U87mg) was provided by Iranian Biological Research Center (Tehran, Iran).

\section{METHODS}

\section{Experimental design of ART-NLCs}

Design of experiment and planning for appropriate formulation composition and process condition is an efficient approach to produce valid and conclusive data to achieve the optimized formulation. In the current study, an 8-run, 7-factor, 2-level Taguchi design employed to prepare a polynomial model for achieving an optimized formulation using Design Expert $7^{\circledR}$ (Stat-Ease Inc., Minneapolis, MN). Seven factors including solid lipid type, amount of solid lipids, quantity of oleic acid, organic phase volume, surfactant type, surfactant concentration and sonication time were defined in two levels to achieve characterization, optimization and prediction purposes. All formulations were made in the laboratory and then evaluated for responses including particle size (PS), zeta potential (ZP), polydispersity index (PDI), percent of entrapment efficiency (EE \%) and mean release time (MRT). Table 1 shows the studied independent variables (factors) and their corresponding levels as well as the dependent variables (responses). The experiment design matrices suggested by the software are listed in Table 2. The experimental results were analyzed by Design Expert $7^{\circledR}$.

\section{Preparation of ART-NLCs}

ART-NLCs were prepared using emulsificationsolvent evaporation method followed by probe sonication. Lipid phase including cholesterol, $\mathrm{Compritol}^{\circledR}$, oleic acid, stearylamine, soy lecithin, and ART was dissolved in dichloromethane at room temperature. Aqueous phase contained various concentrations of Poloxamer 188 or Tween 80. Lipid phase was added to the aqueous phase by rapid injection at room temperature while the mixture was homogenizing by homogenizer at $2000 \mathrm{rpm}$. The resulting pre-emulsion was then ultrasonicated for 2 $\min$ at 40-watt power using a probe-sonicator (Baldelin, Berlin, Germany) with a TT13 probe. To evaporate the solvent, the obtained nanoemulsion was stirred at $400 \mathrm{rpm}$ for $3 \mathrm{~h}$. blank nanoparticles were prepared using the same method as explained above, but without the drug.

\section{Determination of PS, PDI and ZP of ART-NLCs} PS, PDI and ZP were measured by photon correlation spectroscopy using Zetasizer Nano ZS (Malvern Instruments Ltd, Malvern, UK). All measurements were carried out at $25{ }^{\circ} \mathrm{C}$.

Table 1. Independent variables (factors) and dependent variables (responses) as well as their levels in the Taguchi design.

\begin{tabular}{|c|c|c|c|}
\hline \multirow[b]{2}{*}{ Independent variables (factors) } & \multicolumn{2}{|c|}{ Levels } & \multirow[b]{2}{*}{ Dependent variables (responses) } \\
\hline & 1 & 2 & \\
\hline $\mathrm{X}_{1}$, Solid lipid type & CHOL & $\mathrm{COM}$ & $\mathrm{Y}_{1}$, Particle size $(\mathrm{nm})$ \\
\hline $\mathrm{X}_{2}$, Amount of solid lipids (mg) & 10 & 20 & $\mathrm{Y}_{2}$, Zeta potential $(\mathrm{mV})$ \\
\hline $\mathrm{X}_{3}$, Amount of oleic acid (mg) & 5 & 10 & $\mathrm{Y}_{3}$, Poly dispersity index \\
\hline $\mathrm{X}_{4}$, Organic phase volume (mL) & 2.5 & 5 & $\mathrm{Y}_{4}$, Entrapment efficiency $(\%)$ \\
\hline $\mathrm{X}_{5}$, Surfactant type & PLX & Tween & $\mathrm{Y}_{5}$, Mean release time $(\mathrm{h})$ \\
\hline $\mathrm{X}_{6}$, Amount of surfactant $(\%)$ & 0.25 & 0.50 & \\
\hline $\mathrm{X}_{7}$, Sonication time (min) & 2 & 4 & \\
\hline
\end{tabular}

NB: Fixed quantities of stearylamine $(5 \mathrm{mg})$, artemisinin $(2 \mathrm{mg})$ and soy lecithin $(2 \mathrm{mg})$ used in all formulations. CHOL, Cholesterol; COM, Compritol ${ }^{\circledR}$; PLX, Poloxamer; 
J Pharm Pharm Sci (www.cspsCanada.org) 21(1s), 225s - 241s, 2018

Table 2. Designed formulations for the evaluation of artemisinin-NLCs using Taguchi design.

\begin{tabular}{|c|c|c|c|c|c|c|c|}
\hline Formulations & $\begin{array}{l}\text { solid lipid } \\
\text { type }\end{array}$ & $\begin{array}{l}\text { solid lipid } \\
\text { content } \\
\text { (mg) }\end{array}$ & $\begin{array}{l}\text { oleic acid } \\
\text { content } \\
\text { (mg) }\end{array}$ & $\begin{array}{l}\text { organic phase } \\
\text { volume }(\mathrm{mL})\end{array}$ & $\begin{array}{l}\text { surfactant } \\
\text { type }\end{array}$ & $\begin{array}{l}\text { Surfactant } \\
\text { content } \\
(\%)\end{array}$ & $\begin{array}{l}\text { sonication } \\
\text { time (min) }\end{array}$ \\
\hline F1 & Cholesterol & 10 & 5 & 2.5 & Poloxamer & 0.25 & 2 \\
\hline F2 & Compritol $^{\circledR}$ & 20 & 5 & 5 & Poloxamer & 0.25 & 4 \\
\hline F3 & Cholesterol & 10 & 5 & 5 & Tween 80 & 0.50 & 4 \\
\hline F4 & Compritol $^{\circledR}$ & 20 & 5 & 2.5 & Tween 80 & 0.50 & 2 \\
\hline F5 & Cholesterol & 20 & 10 & 5 & Poloxamer & 0.50 & 2 \\
\hline F6 & Compritol $^{\circledR}$ & 10 & 10 & 2.5 & Poloxamer & 0.50 & 4 \\
\hline F7 & Cholesterol & 20 & 10 & 2.5 & Tween 80 & 0.25 & 4 \\
\hline F8 & Compritol $^{\circledR}$ & 10 & 10 & 5 & Tween 80 & 0.25 & 2 \\
\hline
\end{tabular}

\section{Determination of ART concentration}

UV absorption of various concentrations of artemisinin in release medium and supernatants of EE experiment of nanoparticles reacting with sodium hydroxide were measured spectrophotometrically at $292 \mathrm{~nm}$. ART has a very weak UV absorption band centered at $212.5 \mathrm{~nm}$ and can react with sodium hydroxide easily to convert to Q292 giving rise to an intensified UV band at 292 $\mathrm{nm}$ (32). Solutions of ART was exposed to sodium hydroxide for $5 \mathrm{~min}$ to produce Q292 being stable for few weeks. UV spectrum obtained in this study provides very important experimental basis for the UV measurements of the ART. Therefore, the method was validated for linearity, accuracy and precision. To $1 \mathrm{~mL}$ of ART solution in phosphate buffer $\mathrm{pH} 7.4$ containing $0.2 \%$ Tween 80 at $37{ }^{\circ} \mathrm{C}$ was added $0.7 \mathrm{~mL} \mathrm{NaOH} 0.2 \%$. After 5 minutes, Q292 concentration was measured spectrophotometrically at $292 \mathrm{~nm}$ using a UV-VIS spectrophotometer. The calibration curve of ART was linear in the concentration range $1-40 \mu \mathrm{g} / \mathrm{mL}\left(\mathrm{r}^{2}\right.$ $=0.997)$. The inter- and intra-day precision and accuracy was less than $11.6 \%$.

\section{Determination of entrapment efficiency}

For determination of EE of ART in the NLCs, dialysis method was used. Two $\mathrm{mL}$ of the drugloaded NLCs were placed into the dialysis bag (MW cutoff $8 \mathrm{kDa}$, Float-A-Lyser®. G2, Sigma) and immersed in a plastic tube containing $10 \mathrm{~mL}$ phosphate-buffer saline (PBS) for 30 minute while stirring at $400 \mathrm{rpm}$. The concentration of ART in dialysate was determined by measuring the UV absorbance at $292 \mathrm{~nm}$ using a UV-VIS spectrophotometer using previously constructed calibration curve. After calculating the quantity of free drug in the buffer, the drug $\mathrm{EE}$ in the nanoparticles were calculated using following equation.

$$
E E \%=\left(\frac{W i-W d}{W i}\right) \times 100
$$

where, $\mathrm{W}_{\mathrm{i}}$ is the weight of drug initially added in the system, $W_{d}$ is the drug quantity measured in the dialysate after dialysis.

\section{In vitro drug release experiment}

In vitro release studies were performed using the dialysis bag method, modified to maintain a sink condition and achieve satisfactory reproducibility. The formulation was subjected to in vitro release studies using $45 \mathrm{~mL}$ of $0.1 \mathrm{M}$ phosphate buffer solution ( $\mathrm{pH} 7.4$ ) containing $0.2 \%$ Tween 80 . The solution agitated at $400 \mathrm{rpm}$, which maintained at 37 $\pm 0.5{ }^{\circ} \mathrm{C}$. Five $\mathrm{mL}$ of ART-NLC dispersion was transferred into the dialysis bag with molecular weight cutoff of $12,000 \mathrm{Da}$ with the two ends fixed by thread and suspended in to the preheated dissolution media. Aliquots of $500 \mu \mathrm{L}$ were withdrawn at predetermined time intervals up to 72 $\mathrm{h}$ and replaced with fresh medium maintained at the same temperature. ART content in the samples was determined by the described spectrophotometric method. Based on the release profiles, MRT was calculated using equation below.

$$
M R T=\frac{\sum_{i=1}^{n} t \text { mid } \times \Delta M i}{\sum_{i=1}^{n} \Delta M i}
$$

where, $\mathrm{i}$ is the sampling number, $\mathrm{n}$ the number of dissolution sample time, $t_{\text {mid }}$ the time at midpoint between $t_{i}$ and $t_{i-1}$ [easily calculated with the expression $\left.\left(\mathrm{t}_{\mathrm{i}}+\mathrm{t}_{\mathrm{i}-1}\right) / 2\right]$ and $\Delta \mathrm{M}_{\mathrm{i}}$ is the additional amount of drug dissolved between $t_{i}$ and $t_{i-1}(20)$ 


\section{Optimization}

The optimized formulation was selected by the Design Expert $7^{\circledR}$ using computer optimization process and corresponding dependent variables (responses) including PS, PDI, ZP, EE and MRT were predicted based on the previous modeling achieved by the software. The optimized formulation was then prepared within the laboratory, and all the dependent variables were determined practically. Based on the predicted and actual responses, the error percent was calculated. Optimized formulation adopted in this step was used for conjugation with transferrin.

\section{XRD analysis}

X-ray diffraction analyses of lyophilized ART, blank NLCs, ART-NLCs, and bulk matrix with lyophilized ART were carried out with X-ray diffractometer (D8ADVANCE, Bruker, Germany) in the range of $5-80^{\circ}$. A $\mathrm{Cu}-\mathrm{K} \alpha$ radiation source was used, and the scanning rate was $5{ }^{\circ} \mathrm{C} / \mathrm{min}$. Lyophilized ART was prepared by dissolving ART in an aqueous system containing $0.2 \%(\mathrm{w} / \mathrm{v})$ Tween 80 by stirring for 15 $\mathrm{min}$ at $400 \mathrm{rpm}$. The samples were analyzed after vacuum freeze drying.

\section{Conjugation of NLCs with transferrin}

To obtain transferrin (TF)-conjugated ART-NLCs (TF-ART-NLCs), TF was covalently coupled by its carboxylic group to the amine group of stearylamine present on the surface of the preformed adopted ART-NLCs using the method previously suggested by Gupta, et al. (23). Briefly, ART-NLCs were suspended in phosphate buffer $(\mathrm{PH}, 7.4)$ containing $\mathrm{TF}$ at 20:80 TF to lipid ratio and EDC as coupling agent. The mixture incubated for $2 \mathrm{~h}$ at room temperature. Excessive unbound TF and EDC were removed by passing the mixture through a Sephadex G-50 column.

\section{TF-conjugated NLC analysis}

To observe the effects of transferrin conjugation on NLCs, TF-ART-NLCs were analyzed in terms of PS, $\mathrm{ZP}, \mathrm{PDI}, \mathrm{EE}$ and release behavior.

\section{Determination of coupling efficiency}

The amount of transferrin conjugated on the surface of NLCs was determined using an immunoturbidimetric assay using COBAS INTEGRA systems. Briefly, $1 \mathrm{~mL}$ TF-conjugated ART-NLCs suspension was transferred into an Eppendorf tube and centrifuged at 20,000 rpm for 10 min. The supernatant was poured into another
Eppendorf tube and the absorbance of the sample was measured at $340 \mathrm{~nm}$. The average quantity of protein conjugated to the surface of the NLCs was calculated indirectly by measuring the amount of unconjugated protein. Coupling efficiency was measured and expressed as mg transferrin per mmol phospholipids.

\section{FTIR analysis}

Fourier transform infrared (FTIR) spectrophotometer (6020, Jasco, Japan) was used to confirm the conjugation between $\mathrm{TF}$ and stearylamine. For this confirmation we used FTIR spectra of TF-ART-NLCs and physical mixture of TF and lyophilized ART-NLC. The scanning range was $400-4000 \mathrm{~cm}^{-1}$ and the resolution used was 4 $\mathrm{cm}^{-1}$.

\section{Cell culture}

U-87MG, human brain cancer cells, were maintained in DMEM low glucose supplemented with $15 \%$ $(\mathrm{v} / \mathrm{v})$ FBS and $1 \%$ penicillin-streptomycin and MEM at $37{ }^{\circ} \mathrm{C}$ and $5 \% \mathrm{CO} 2$. Cells were subcultured frequently using trypsin/EDTA.

\section{Scanning electron microscopy observation}

The surface morphology and size of the NPs were investigated by a scanning electron microscope (Zeiss, Germany). Samples were mounted on metal stubs and sputter-coated with gold for $4 \mathrm{~min}$, prior to examination.

\section{In vitro cytotoxicity assay}

Cytotoxicity of the blank NLCs, TF-NLCs, free ART, ART-NLCs, and TF-ART-NLCs were evaluated against U-87MG cancer cell using MTT assay. The cells were seeded at $4 \times 10^{4}$ cells/well in a 96-well culture plate (SPL Life Sciences). When the cell confluence reached to $75 \%$, the cells were incubated with samples for $48 \mathrm{~h}$ at the equivalent ART concentrations of $0.2-8 \mu \mathrm{M}$. Then, $20 \mu \mathrm{L}$ MTT solution $(5 \mathrm{mg} / \mathrm{mL}$ in $0.02 \mathrm{M}$ PBS) was added to each well and the plate was incubated for another 4 h. After that, unreacted MTT and medium was removed and the formazan crystals in cells were dissolved in $150 \mathrm{~mL}$ dimethyl sulfoxide. The absorbance was measured at $570 \mathrm{~nm}$ using enzymelinked immunosorbent assay reader (Stat Fax-2100; Awareness Technology Inc., Palm City, FL). Untreated cells were taken as the negative control with $100 \%$ viability and the blank culture medium was used as the control. Cell viability for each sample was calculated using following equation: 


$$
\text { Cell survival } \%=\left(\frac{\text { mean absorbance of each group }- \text { mean absorbance of the blank }}{\text { mean absorbance of negative control }- \text { mean absorbance of the blank }}\right) \times 100
$$

\section{STATISTICAL ANALYSIS}

Data are expressed as means of three separate experiments and were compared by independent sample t-test for two groups, and one-way analysis of variance (ANOVA) following LSD post hoc test for multiple groups. A $p$-value $<0.05$ was considered statistically significant in all cases. All statistical analyses were performed using SPSS (v18).

\section{RESULTS}

\section{Taguchi design analysis}

The impact of several formulation and process parameters including solid lipid type, solid lipid amount, surfactant type, surfactant concentration, liquid lipid amount, organic phase volume and sonication time were assessed using a Taguchi design in order to achieve optimal preparation condition. A number of nanoparticle formulations (Table 1) were prepared and the basic characteristics of the products were determined and analyzed with Design Expert $7^{\circledR}$. The size of NLCs ranged from 61.9 to $627 \mathrm{~nm}$ and was affected by surfactant type, surfactant quantity and sonication time. All formulations exhibited positive $\mathrm{ZP}$ values ranging 16.7-30.3 mV, which was more affected by oleic acid quantity and surfactant type $(P<0.05)$. The EE for all formulations was greater than about $60 \%$ and mostly affected by solid and liquid quantities $(P<$ 0.05) (Figure 1 and Table 3).

\section{In vitro drug release from ART-NLCs}

As illustrated in Figure 2 (A and B), between 50 to $80 \%$ of ART in different formulations was released from the NLCs within $96 \mathrm{~h}$. The release profiles show a faster release at very early stages of the release profile followed by a sustained manner suitable for controlled release delivery of this drug. As illustrated in Figure 1, Figure 2, and Table 3, MRT was considerably influenced by solid lipid amount and to a lesser extent by oleic acid and surfactant containments.

\section{Optimization}

Based on the Design Expert $7^{\circledR}$ modeling output and a desirability factor of $81 \%$, following values for tested variables are suggested by the software for preparation of the optimized formulation. Compritol $^{\circledR}, 20 \mathrm{mg}$; Tween 80, 0.25\%; oleic acid, 5 $\mathrm{mg}$; dichloromethane, $2.5 \mathrm{~mL}$; and 4 minutes sonication. The optimized formulation was then prepared practically in the laboratory and was evaluated in terms of PS, PDI, ZP, EE and MRT, as well as the error percent of predicted and observed values. Table 4 shows responses constraints, prediction goal, and the average values for every response both predicted by the model and obtained through the evaluation of prepared optimized formulation.

Table 3. Formulations generated by the Taguchi design with their respective responses $(n=3)$.

\begin{tabular}{|c|c|c|c|c|c|}
\hline Formulations & PS (nm) & PDI & $\mathrm{ZP}(\mathrm{mV})$ & EE (\%) & MRT (h) \\
\hline $\mathrm{F} 1$ & $627 \pm 97.5$ & $0.551 \pm 0.012$ & $26.2 \pm 2.1$ & $63.4 \pm 8.9$ & $19.5 \pm 0.8$ \\
\hline $\mathrm{F} 2$ & $440 \pm 53.5$ & $0.608 \pm 0.015$ & $30.3 \pm 2.8$ & $85.3 \pm 9.3$ & $26.4 \pm 1.1$ \\
\hline F3 & $87.9 \pm 9.2$ & $0.479 \pm 0.010$ & $26.7 \pm 2.6$ & $59.1 \pm 7.8$ & $11.0 \pm 0.3$ \\
\hline $\mathrm{F} 4$ & $236 \pm 38.1$ & $0.677 \pm 0.013$ & $22.6 \pm 2.1$ & $85.3 \pm 8.9$ & $24.0 \pm 1.3$ \\
\hline F5 & $406 \pm 47.1$ & $0.684 \pm 0.014$ & $18.1 \pm 1.2$ & $80.3 \pm 8.1$ & $17.6 \pm 0.9$ \\
\hline F6 & $212 \pm 15.8$ & $0.272 \pm 0.008$ & $18.9 \pm 1.3$ & $75.1 \pm 7.9$ & $8.40 \pm 0.2$ \\
\hline F7 & $61.9 \pm 6.1$ & $0.464 \pm 0.011$ & $17.6 \pm 1.1$ & $83.1 \pm 8.1$ & $20.8 \pm 1.0$ \\
\hline F8 & $385 \pm 33.2$ & $0.600 \pm 0.012$ & $16.7 \pm 0.9$ & $75.7 \pm 7.8$ & $15.7 \pm 0.6$ \\
\hline
\end{tabular}

Abbreviations: PS, particle size; PDI, poly dispersity index; ZP, zeta potential; EE, entrapment efficiency; MRT, mean release time. 
The acceptable agreement between the observed values and the values predicted by the model and the slight error percent confirm the validation, reliability, and adequate precision of our method for the prediction of optimized conditions in the domain of levels chosen for the independent variables.

\section{XRD analysis of NLCs}

The X-ray diffraction patterns of lyophilized ART, blank NLCs, ART-NLCs and bulk matrix with lyophilized ART are illustrated in Figure 3. The sharp peaks of ART show the crystalline nature of its molecules (Figure 3A). Diffraction patterns of blank NLCs (Figure 3B) and ART-NLCs (Figure 3C) showed less ordered crystals. Absence of sharp peaks in ART-NLCs indicates high drug EE in NLCs as ART is entrapped in the lipid core of NLCs in the amorphous state. There was not much difference in the pattern of ART-NLCs and blank NLCs, indicating that the addition of ART has not changed the nature of NLCs. Presence of sharp peaks in bulk matrix (Figure 3D) shows that the physical compound of ART and blank NLCs does not represent loaded NLCs as ART still is not in the lipid core of the particles.

\section{TF-conjugated NLC analysis}

The physicochemical characteristics of TFconjugated ART-NLCs (TF-ART-NLCs) including PS, PDI, ZP, EE, MRT, and conjugation efficiency were assessed. Physicochemical characteristics of optimized ART-NLCs before and after conjugation with TF are demonstrated in Table 5. Size and zeta potential distribution of TF-ART-NLCs are also illustrated in Figure 4A and 4B. Release profile of optimized ART-NLC and TF-ART-NLCs are shown in Figure 5.

\section{FTIR analysis}

Fig. 6 shows FTIR spectra of TF-conjugated ARTNLCs (A) and physical mixture (B) of all components used in the preparation of optimized formulation. In TF-conjugated ART-NLCs, the linkage between - $\mathrm{COOH}$ group of $\mathrm{TF}$ and $-\mathrm{NH} 2$ group of stearylamine was confirmed by the amide (CO-NH-) stretching peak at $1653.6 \mathrm{~cm}^{-1}$. In both TFART-NLCs and physically mixed components, the absorption bands at 3333.4 and $3407.6 \mathrm{~cm}^{-1}$ were due to the terminal hydroxyl groups.

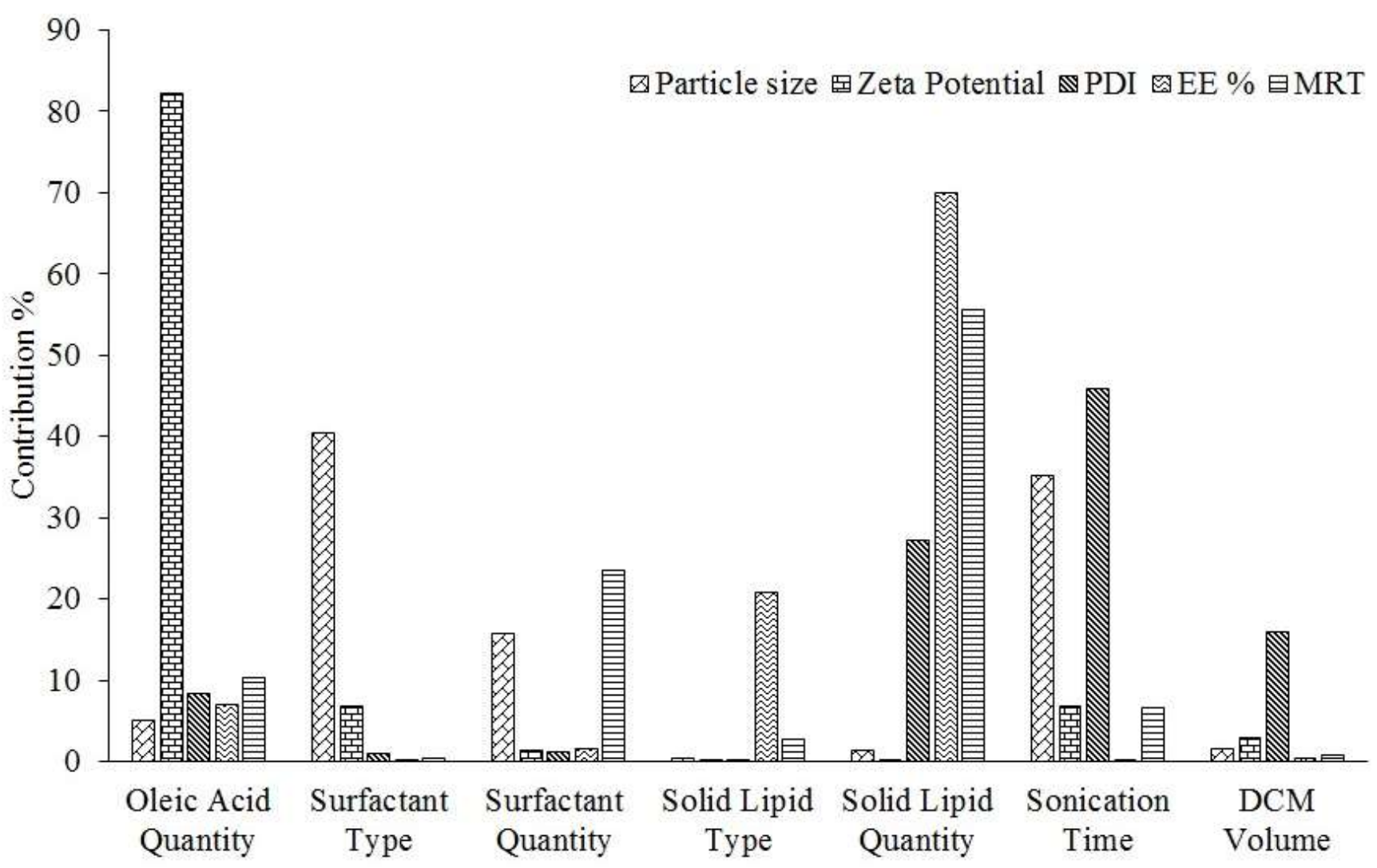

Figure 1. Contribution percentage of independent variables on various responses analyzed using Taguchi design 

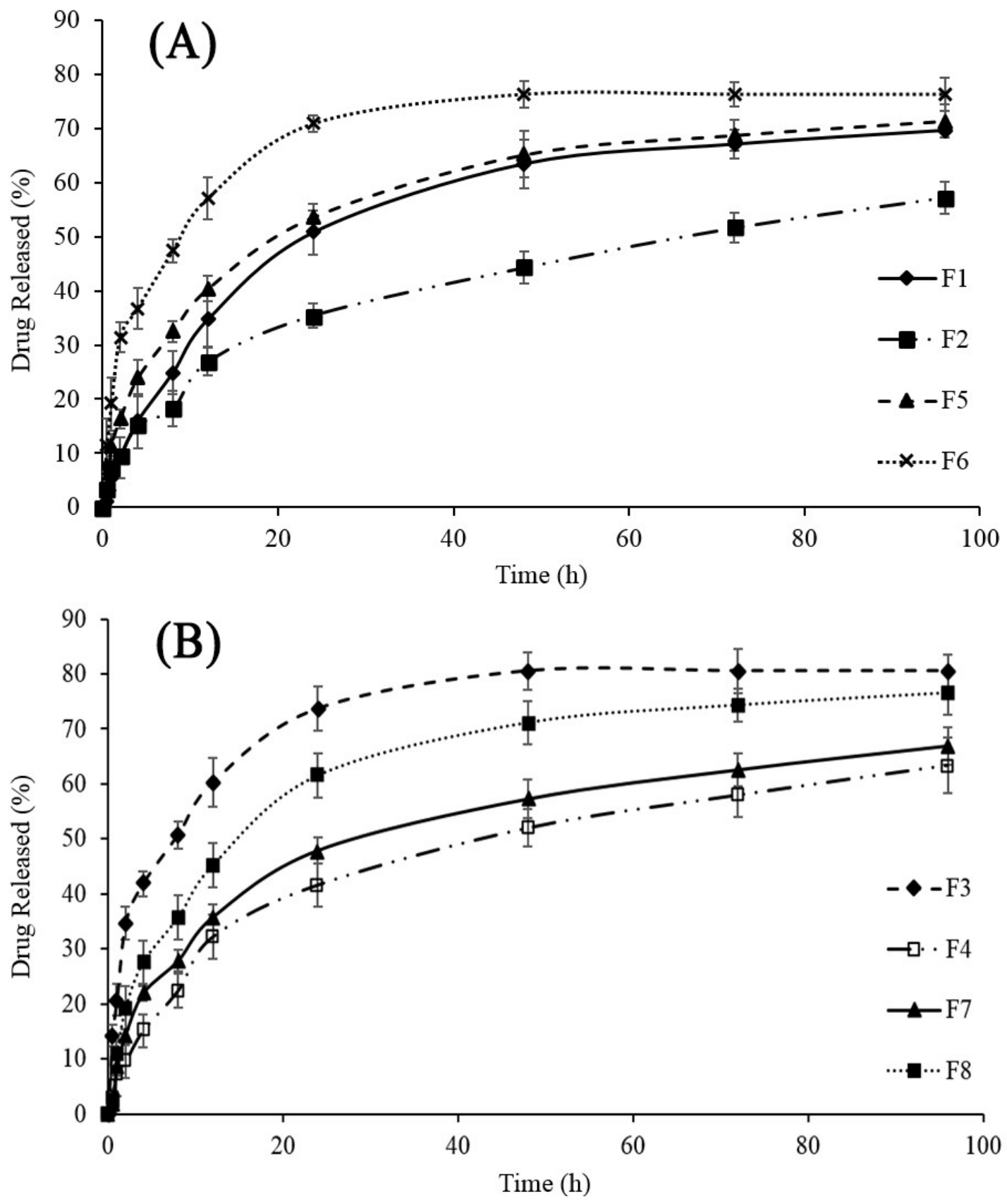

Figure 2. (A), release profile of F1, F2, F5 and F6 and (B), release profile of F3, F4, F7 and F8 (n=3)

Table 4. Constraints, target goals, and accuracy for predicted and actual responses for the optimal formulation $(\mathrm{n}=3)$.

\begin{tabular}{llllll} 
Responses & Constraints & Prediction goal & Actual values & Predicted values & Error (\%) \\
\hline PS (nm) & $61.9-627.0$ & Minimize & $145.0 \pm 12.5$ & 166.2 & 12.8 \\
PDI & $0.272-0.684$ & Minimize & $0.513 \pm 0.021$ & 0.532 & 3.6 \\
ZP (mV) & $16.7-30.3$ & Maximize & $24.3 \pm 1.5$ & 26.2 & 7.3 \\
EE (\%) & $59.1-85.3$ & Maximize & $82.3 \pm 7.3$ & 86.7 & 5.1 \\
MRT (h) & $8.4-26.4$ & In the range & $24.0 \pm 1.1$ & 26.8 & 10.4 \\
\hline
\end{tabular}

Abbreviations: PS, particle size; PDI, polydispersity index; ZP, zeta potential; EE, entrapment efficiency; MRT, mean release time. 

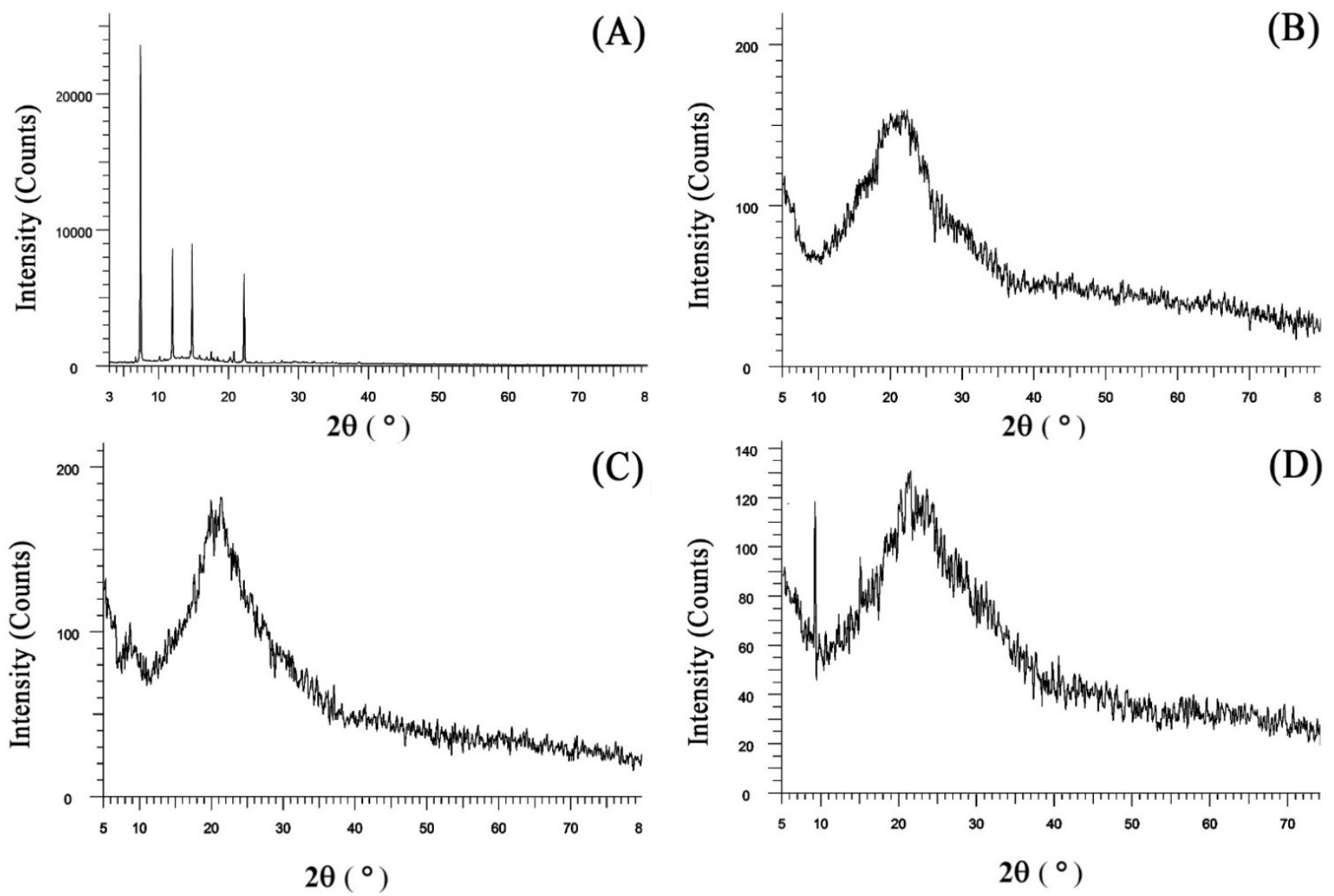

Figure 3. X-ray diffraction patterns of lyophilized ART (A), blank NLCs (B), ART-NLCs (C), and bulk matrix of lyophilized ART and blank NLCs (D).

Table 5. Dependent variables of optimized formulation ART-NLC and TF-ART-NLCs targeted formulation

\begin{tabular}{lllllll}
\hline Formulations & PS $(\mathbf{n m})$ & PDI & ZP $(\mathbf{m V})$ & EE $(\%)$ & MRT (h) & CE(gTf/mol SA) \\
\hline ART-NLC & $145.0 \pm 12.5$ & $0.513 \pm 0.021$ & $24.3 \pm 1.5$ & $82.3 \pm 7.3$ & $24.0 \pm 1.1$ & NA \\
TF-ART-NLC & $170.0 \pm 9.5^{*}$ & $0.331 \pm 0.014$ & $14.1 \pm 0.8$ & $68.8 \pm 6.4$ & $29.2 \pm 1.6$ & 135.1 \\
\hline
\end{tabular}

Abbreviations: PS, particle size; PDI, polydispersity index; ZP, zeta potential; EE, entrapment efficiency; MRT, mean release time; CE, coupling efficiency; SA, stearylamine. *Not significantly different from unconjugated ART-NLC $(P>$ $0.05)$.

\section{Scanning electron microscopy observation}

The morphology of the optimized nanoparticles visualized using scanning electron microscopy (SEM) imaging (Figure 7). This image clearly displays that nanoparticles have spherical shapes and PSs around $150 \mathrm{~nm}$. The scan also reveals that the particles have a more or less uniform size distribution.

\section{In vitro cytotoxicity assay}

Cytotoxicity of blank NLCs, TF-NLCs, free ART, ART-NLCs, and TF-ART-NLCs were evaluated against U-87MG cells. As shown in Figure 8, blank NLCs and TF-NLCs did not show any measurable toxicity even at high-test concentrations. Considerable cytotoxicity was observed when the cells were exposed to the TF-ART-NLC compared with ART-NLCs, free drug and blank formulation at concentration 0.4 to $4 \mu \mathrm{M}(P<0.001)$, while the cell cytotoxicity of ART-NLCs was much lower and viability of cells treated with ART-NLCs showed a significant difference compared to blank NLCs at higher concentrations ( $>6 \mu \mathrm{M}, P<0.05$ ). Significantly, free ART killed fewer cells compared with ART-NLCs and TF-ART-NLC at concentration $8 \mu \mathrm{M}(P<0.05)$, while at lower concentrations, free ART was not toxic at all. 
(A)

$\begin{array}{rlllll} & & \text { Diam. (nm) } & \text { \% Intensity } & \text { Width (nm) } \\ \text { Z-Average (d.nm): } 170.0 & \text { Peak 1: } & 180.3 & 88.4 & 45.43 \\ \text { Pdl: } & 0.331 & \text { Peak 2: } & 25.18 & 11.6 & 5.345 \\ \text { Intercept: } 0.936 & \text { Peak 3: } & 0.000 & 0.0 & 0.000\end{array}$

Result quality : Refer to quality report

Size Distribution by Intensity

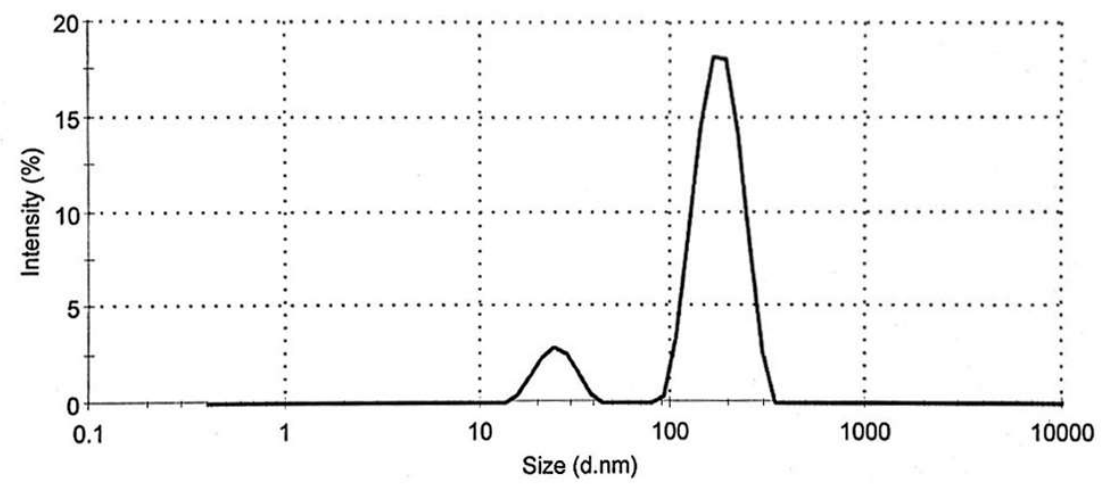

(B)

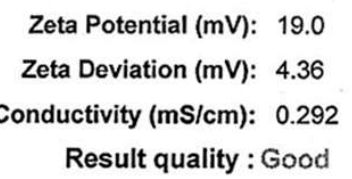

$\begin{array}{llll} & \text { Mean }(\mathrm{mV}) & \text { Area }(\%) & \text { Width }(\mathrm{mV}) \\ \text { Peak 1: } & 19.0 & 100.0 & 4.36 \\ \text { Peak 2: } & 0.00 & 0.0 & 0.00 \\ \text { Peak 3: } & 0.00 & 0.0 & 0.00\end{array}$

Zeta Potential Distribution

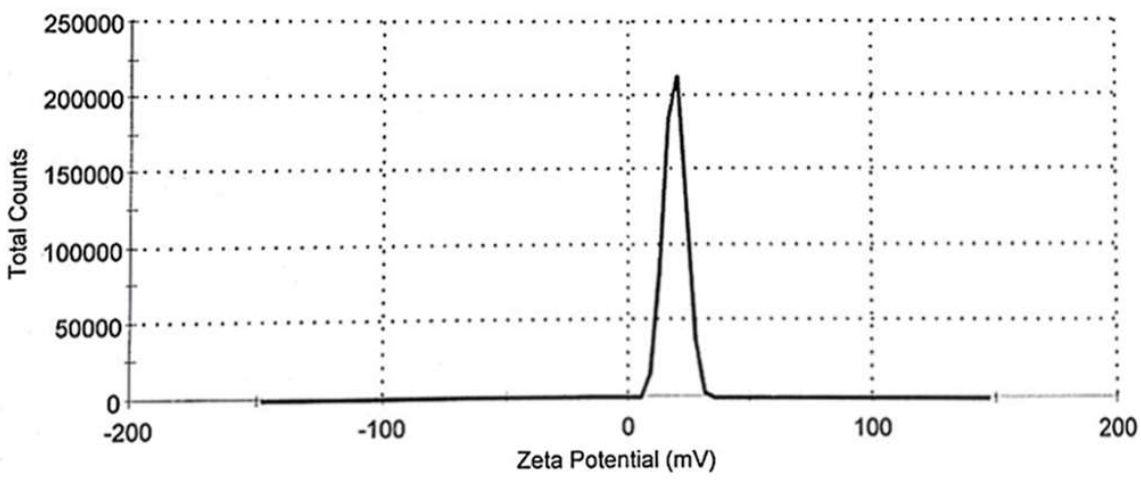

Figure 4. Size distribution (A) and zeta potential distribution (B) of TF-ART-NLCs

\section{DISCUSSION}

Numerous drug delivery carriers have so far been studied for the delivery of ART into the cancer cells. NLCs have been developed as groundbreaking carrier systems having more advantages over other colloidal delivery systems. By using optimized quantity of solid and liquid lipids, the particles become solid after cooling, but do not crystallize that leads to more imperfections in the crystal and higher drug loading. In the current study, we have developed NLCs loaded with ART, which can be targeted to human brain cancer cells. A Taguchi design with seven factors and two levels was applied 
to optimize the formulation. Eight formulations were prepared using the emulsion-solvent evaporation technique and several formulation parameters including solid lipid type, solid lipid quantity, oleic acid amount, surfactant type, surfactant concentration and sonication time were assessed in order to achieve optimal preparation conditions.

Particle size and size distribution are two important characteristics of nanoparticles affecting drug release profile, bio-distribution, cellular uptake, and protein diffusion. Statistical analysis of the size measurement revealed that the most effective factors on PS was surfactant concentration, surfactant type and sonication time. PS was significantly reduced with increasing of surfactant concentration. Hao, et al. demonstrated that an increase in poloxamer concentration resulted in particle size reduction (33). Surfactants stabilize emulsion by reducing tension between the organic phase and aqueous phase preventing particles aggregation and formation of a stable emulsion with smaller and uniform droplet size leading to the formation of smaller sized nanoparticles with low polydispersity (34). Tween 80 was more effective than poloxamer 188 in reducing particle size. This might be because of higher topological polar surface area of tween (133 $\AA^{2}$ ) compared to poloxamer $\left(25.1 \AA^{2}\right)$. Higher topological polar surface reduces tension between organic phase and aqueous phase producing particles with smaller sizes. In order to obtain emulsified systems, the application of energy is a fundamental step. To verify the influence of this factor on nanoparticle size distribution, sonication time was varied. An increase in the sonication time led to a reduction in the nanoparticles mean diameter possibly by elongation of breaking energy and cavitation, which explain formation and collapse of vapor cavities that make powerful shock waves, and break dispersed liquid (35).

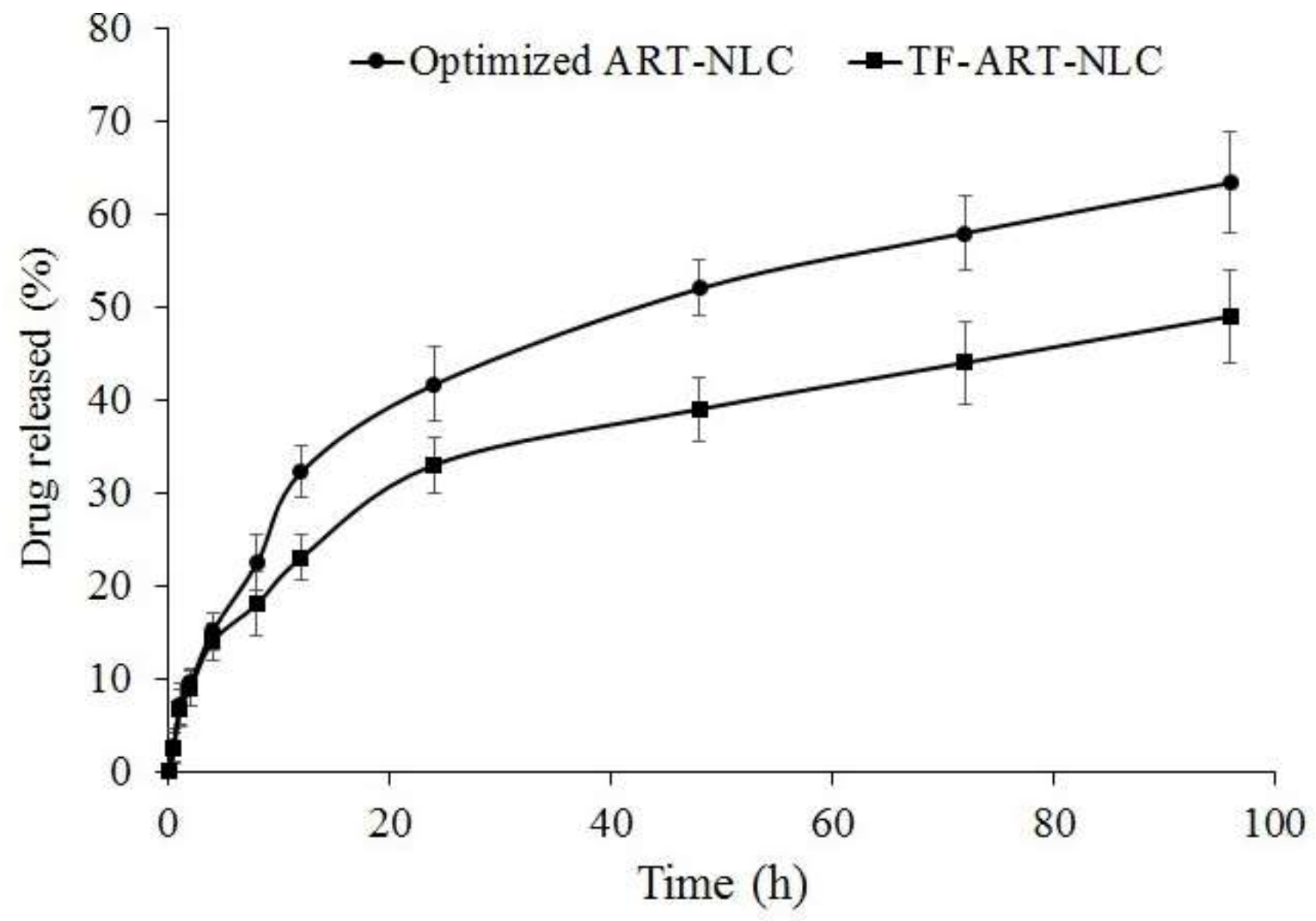

Figure 5. Release profile of optimized ART-NLC and TF-ART-NLCs. 


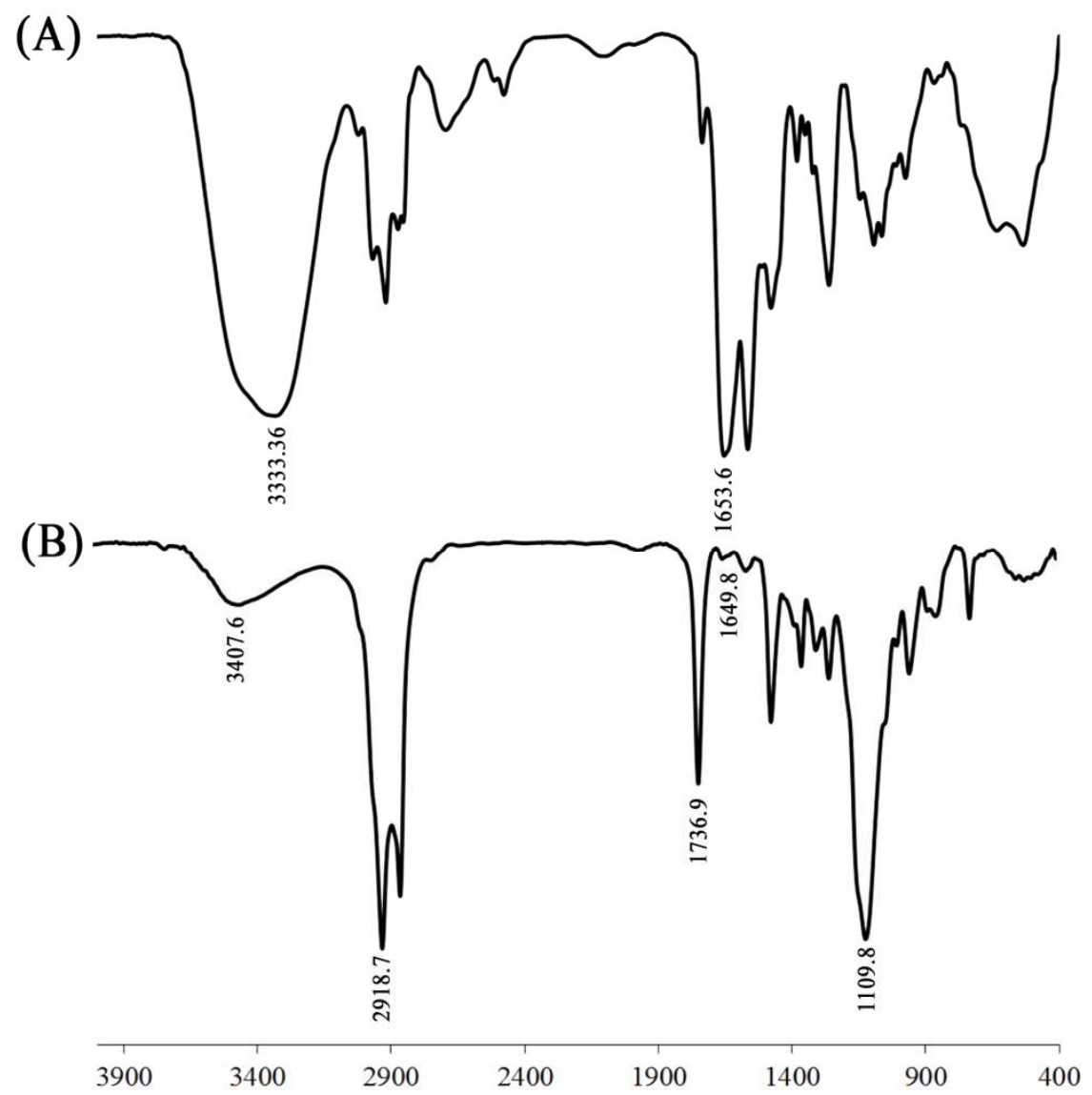

Figure 6. FTIR spectra of (A) TF-conjugated ART-NLCs (B) and physical mixture of all formulation components

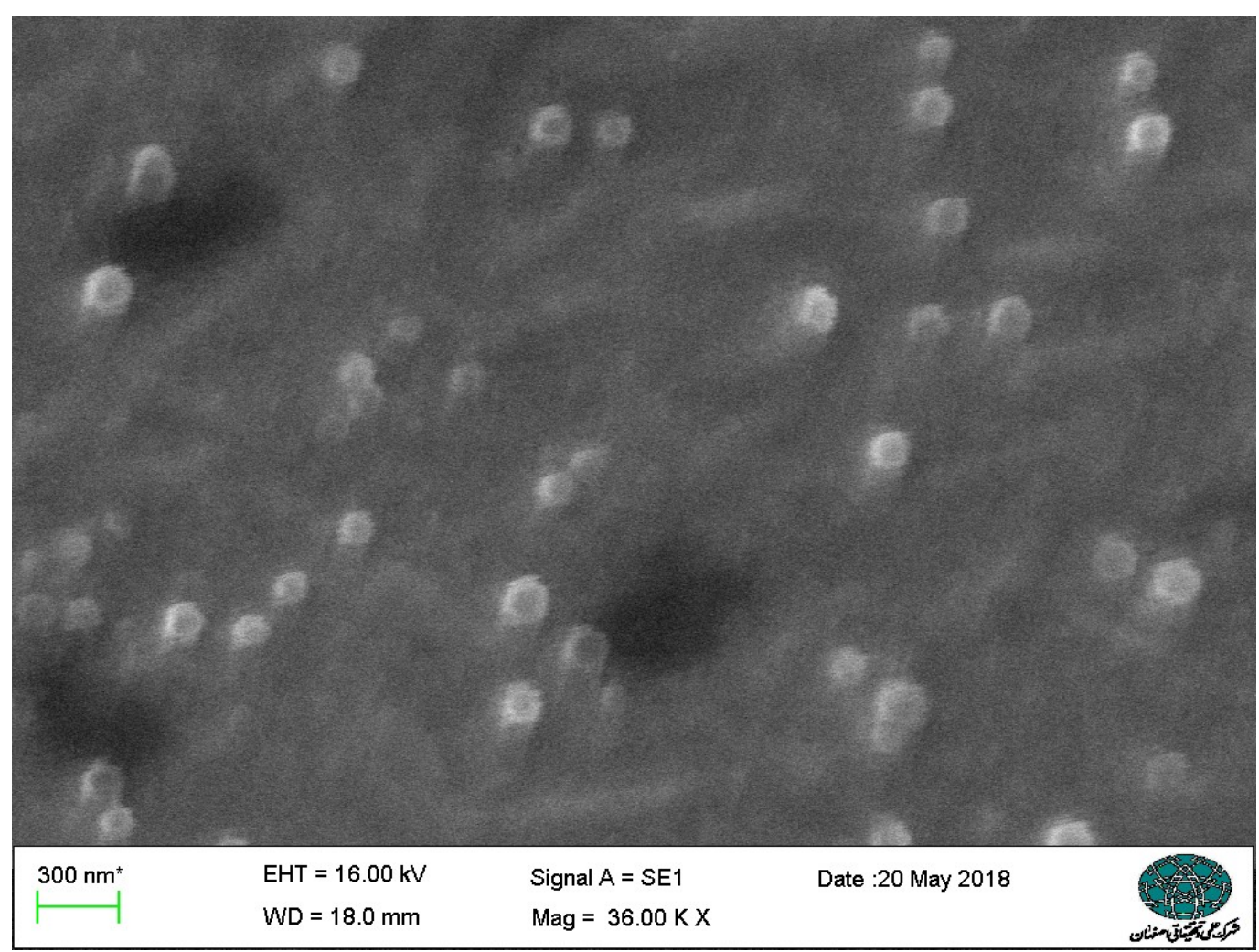

Figure 7. SEM of optimized ART-NLCs. 


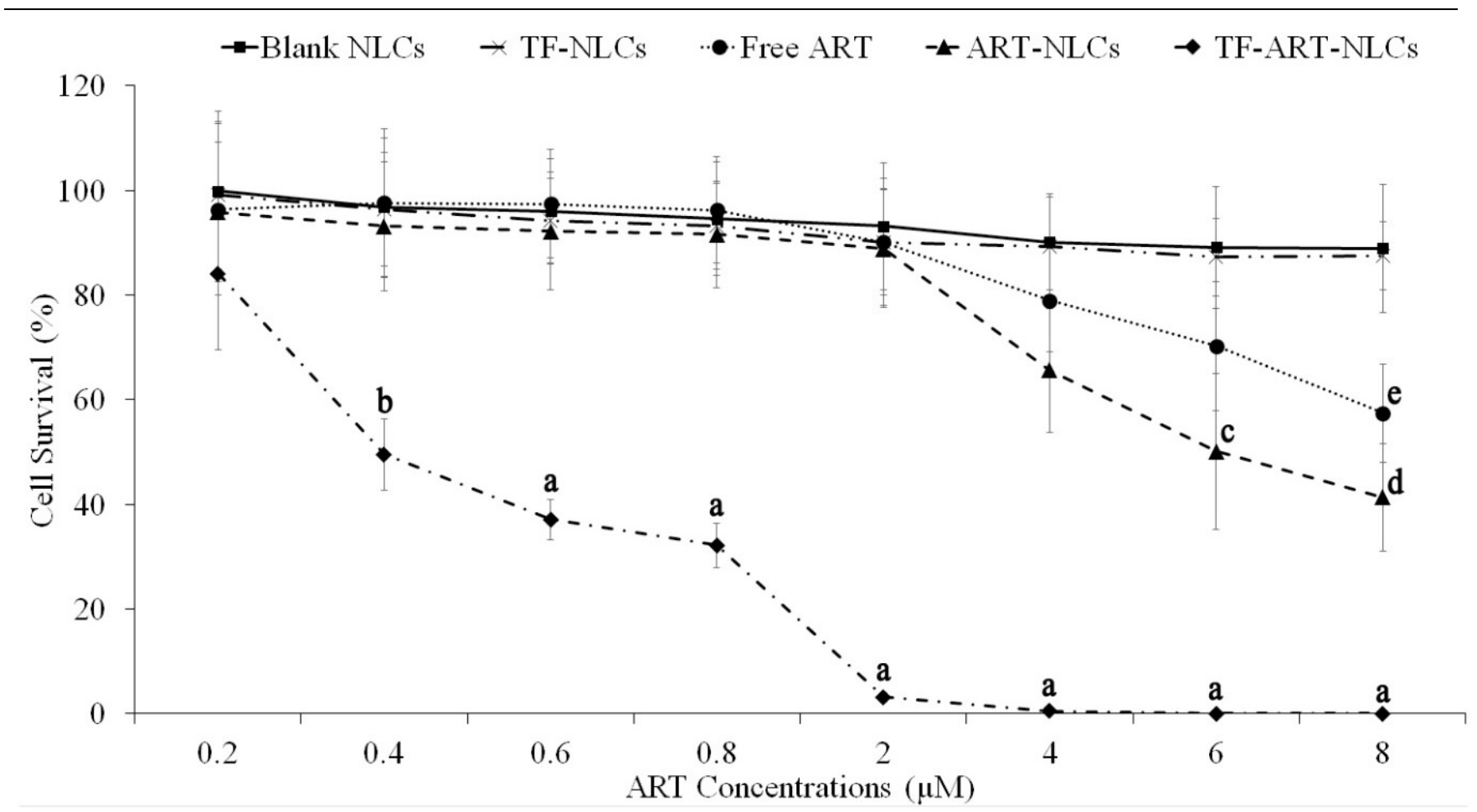

Figure 8. In vitro cytotoxicity of blank NLCs, TF-NLCs, free ART, ART-NLCs, and TF-ART-NLCs evaluated against U$87 \mathrm{MG}$ cell line after $48 \mathrm{~h}$ incubation. Data are plotted as the mean \pm standard deviation $(\mathrm{n}=3)$. ${ }^{\text {a,b }}$ Significantly different from corresponding ART-NLC, Free drug, TF-NLC and blank NLCs $\left({ }^{\mathrm{a}} p<0.001,{ }^{\mathbf{b}} p<0.01\right)$. ${ }^{\mathrm{c}}$ Significantly different from blank NLCs and TF-NLCs $(p<0.05)$. ' Significantly different from blank NLCs and TF-NLCs $(p<0.01)$. ${ }^{\text {eSignificantly different }}$ from blank NLCs and TF-NLCs $(p<0.05)$. Abbreviations: ART, Artemisinin; NLCs, Nanostructured lipid carriers; TR, Transferrin.

Nanoparticles with narrower size distribution are necessary to optimize clinical outcomes. PDI is one of the important indices showing the uniformity of particles. High PDI values indicate broad size distribution that may not result in appropriate clinical achievement. PDI analysis showed that oleic acid concentration, solid lipid quantity, sonication time and organic phase volume significantly affected PDI values. Higher oleic acid content in the nanoparticles significantly decreased PDI because of reduction in the viscosity inside NLCs and consequently reduced surface tension to form smaller and more uniform particles. Similarly, Hu and coworkers showed that greater oleic acid quantities caused higher uniformity in NLCs particle distribution (36). Conversely, increasing the concentration of solid lipid inside the nanoparticles resulted in bigger and less uniform and nonhomogeneous particles. This observation could be attributed to the less efficient emulsification of the solid lipid matrix since inadequate oil quantity is available in the matrix (37). Longer sonication was favored to form nanoparticles with more homogenous size distribution by cavitation phenomena.
The volume of DCM in the emulsion is of great importance to its stability and influences the size distribution of dispersed globules. The organic solvent used in these formulations was immiscible with water and slowly partitioned into the continuous aqueous medium to precipitate the lipid around the drug. This may lead to the formation of relatively nonuniform-shaped nanoparticles.

$\mathrm{ZP}$, the electric potential in the interfacial layer between two phases, is a key factor showing the stability of colloidal dispersion. Particles repel each other if the systems have high positive or negative value of $\mathrm{ZP}$. In the current study, ZP of different formulations laid between 16.7 and $26.2 \mathrm{mV}$. As was reported by Roland et al. ZP values should be at least $10 \mathrm{mV}$ to permit estimate of distinct stability (38). In general, emulsion systems with $\mathrm{ZP}> \pm 30 \mathrm{mV}$ is completely pharmaceutically stable (39). ZP of optimized formulation was $24.3 \mathrm{mV}$ indicating a good stability when prepared as a colloidal system. By increase oleic acid quantity, ZP values were reduced significantly. This might be due to dissociation of this carboxylic acid to an extent in water to yield hydrogen ions. 
As indicated in Table 3, EE was between 59.1 and $85.3 \%$, which demonstrates reasonable drug entrapment for this type of carriers. Increment of oleic acid concentration in formulation led to a significant increase in EE. Souto et al. reported that the addition of liquid lipids in solid lipid particles prevents NLCs to recrystallize after cooling and remain in the amorphous state (40). Crystallization is strongly connected with drug incorporation and higher degree of crystallization reduces drug incorporation in NLCs (41). High EE was also the result of high solubility of the lipophilic drug ART in the lipid matrix. Liu and coworkers showed that an increase in oleic acid concentration increased docetaxel entrapment from $10 \%$ to $40 \%$ in NLCs (42). Another factor that affected EE was solid lipid quantity. EE significantly increased when the amount of incorporated solid lipid was increased from $10 \mathrm{mg}$ to $20 \mathrm{mg}$. This result is in accordance with similar studies reporting higher EE once solid lipid was increased $(43,44)$. Compritol ${ }^{\circledR}$ used as the solid lipid in this study caused greater EE compared to cholesterol $(P<0.05)$. This might be attributable to the crystalline lattice of cholesterol (45) which prevents more efficient entrapment of the drug in nanoparticles. Lipids that make crystal lattice during the aging period cause drug explosion as well (46).

In vitro drug release study is a prerequisite for evaluating the in vivo performance of a drug delivery system. This is because the in vitro drug release profile provides the most sensitive and reliable information for in vivo evaluation that helps in ascertaining the future behavior of the designed formulation with regard to its drug release pattern and the time duration of its action in biological system. Figure 2 shows that ART-loaded formulations released 56.1\%-81.2 \% (respectively for F2 and F3 formulations) of the entrapped drug within $96 \mathrm{~h}$. Caffo et al. showed that suitable range of MRT in targeted brain delivery of antitumor drug nanosystems is 24 to $48 \mathrm{~h}$ (47). Thus, proposed optimized formulation with MRT of $24 \mathrm{~h}$ seems an appropriate system enable to deliver ART to the brain. The release profiles illustrate a faster release rate at very early stages of the drug release and a sustained fashion in later time suitable for controlled release delivery of this drug. Initial faster release of drug might be due to interfacial drug loading. Similar release profiles have been reported in some other studies $(44,48)$. As illustrated in Figure 2 MRT is more affected by surfactant concentration, solid lipid and oleic acid quantities. Release rate became slower once solid lipid quantity was increased from 10 to 20 mg, while increasing oleic acid from level 1 to level 2 considerably decreased MRT values. Alteration in interior viscosity of NLCs should be the reason for the observations. Shen et al. showed that NLCs containing more liquid lipid released their drug content faster compared to SLNs having more solid lipid (49). In accordance with our findings, different studies have demonstrated that higher solid lipid content or lower liquid lipid quantity increased MRT values $(42,44)$. Higher surfactant concentration in external phase caused faster drug release rate. It has been reported previously that increasing the concentration of poloxamer as surfactant can increase the release rate of drug from NLCs (49) probably due to smaller PS increasing specific area and shorter diffusion distance for the drug (50). In addition, higher concentration of surfactant increases the solubility of the drug enhancing its release from the nanoparticles. It is also suggested that the surfactant may fuse with the receiver side, thus altering the barrier properties of the aqueous boundary layer and permeability of the membrane, resulting in high release of the drug from the nanoparticles (51).

In this study, TF-conjugated ART-NLCs were developed to transport ART across the blood brain barrier. Due to the projection of positively charged nitrogen atoms of stearylamine on the surface of the NLCs, TF coupling reaction became possible when mediated by EDC. The amide linkage is formed via covalent conjugation of the carboxyl group of TF with the amino group of the fatty amine present at the surface of the NLCs. Previous studies demonstrated that higher concentration of $\mathrm{TF}$ in conjugation process did not result in a significant increase in the coupling efficiency (43) thus only one lipid to TF ratio was tested in this study.

As illustrated in Table 5, the mean PS of the NLCs was nonsignificantly increased after conjugation with transferrin. This observation which is in agreement with previous studies $(43,48)$ might be due to the large transferrin peptide molecule decorating the surface of NLCs. After TF conjugation, $\mathrm{ZP}$ of the nanoparticles was reduced significantly, which could be due to masking of the cationic charges present on the surface of NLCs. Similar observations have been made in other studies using ferritin (52) or TF (48) as the targeting agent. Percent EE were decreased significantly after TF conjugation. This could be attributed to the negligible drug leaching during the conjugation reaction process caused by agitation $(48,52)$. As it is deduced from Table 5, drug release rate was 
reduced from TF-coupled NLCs as indicated by higher MRT values. Transferrin conjugation may promote structural integrity of TF-encored nanoparticles providing a barrier effect for drug diffusion. These are in agreement with the findings of Soni et al. for TF-coupled liposomes (53).

As shown in Figure 8, cytotoxicity of TF-ARTNLC was intensively greater than non-targeted formulation, blank formulation and free drug. The pronounced cytotoxicity of TF-ART-NLC could be attributed to the faster cellular uptake of the targeted NLCs mediated by transferrin receptors overexpressed on the surface of U-87 cells. Some earlier published reports have demonstrated that specific binding of TF-targeted nanoparticles to TF receptor on the surface of brain cancer cells contributed to an additional pathway through which the drug could be delivered into cell cytoplasm to induce cell apoptosis $(24,25,54-56)$. Interestingly, it has been shown that exposure of nontumor cells to ART produces no or only minimal cytotoxicity (57). Artemisinin is generally regarded a low toxic drug. Neurotoxicity and reproductive toxicity are two problems associated with this agent. However, the extent of the neurotoxicity is dependent on the nature of the compound, on the route of administration, and on the characteristics of the formulation. Moreover, Neurologic signs were seen at high i.m. doses only (15). ART-loaded transferrin-anchored NLCs developed in the current study presented increased water solubility, site specificity, selective targeting, efficient penetration, glioma cell distribution and internalization, and effective delivery across the blood brain barrier with much lower drug concentration, which can improve the efficacy of treatment and decrease the possibility of neurotoxicity.

The in vivo cytotoxicity of ART may also be intensified by the fact that TF-decorated nanoparticles prepared in the current study may carry more $\mathrm{Fe}^{2+}$ towards glioma cells in the brain taken up through TF receptor overexpressed on malignant cells. This idea is supported by the fact that pretreatment of cancer cells with TF significantly increased ART toxicity against U373 and H69VP cell lines compared with ART alone $(57,58)$.

\section{CONCLUSIONS}

The ART-loaded NLCs developed in the current study could potentially be exploited as a delivery system in brain tumors. Our study showed that ARTloaded NLCs can be successfully achieved through the solvent-evaporation method, with appropriate morphological characteristics, high entrapment efficiency and controlled drug release profile suitable for brain administration. Various factors such as solid lipid type, solid lipid content, liquid lipid content, surfactant type, surfactant concentration, organic solvent volume and sonication time can affect PS, PDI, ZP, EE \% and release behavior. The transferrin moiety decorated on the surface of the NLCs helps transportation of drug across blood brain barrier. Results also heightened anticancer effect of the anticancer drug in human brain cancer cells compared to free ART, and other ART-loaded NLCs because of TF receptor mediated endocytosis. Our results provide fundamental data onto the application of transferrin conjugated NLCs in brain delivery system of ART. Future studies should be conducted to test the effectiveness of this system in vivo

\section{REFERENCES}

1. Kleihues P, Louis DN, Scheithauer BW, et al. The WHO classification of tumors of the nervous system. J Neuropathol Exp Neurol. 2002; 61: 215-29.

2. Stupp R, Hegi ME, van den Bent MJ, et al. Changing paradigms: An update on the multidisciplinary management of malignant glioma. Oncologist. 2006; 11: $165-80$

3. Ong BY, Ranganath SH, Lee LY, Lu F, Lee HS, Sahinidis NV, Wang CH. Paclitaxel delivery from PLGA foams for controlled release in post-surgical chemotherapy against glioblastoma multiforme. Biomaterials. 2009;30:3189-3196.

4. Genc DB, Canpolat C, Berrak SG. Clinical features and management of carboplatin-related hypersensitivity reactions in pediatric low-grade glioma. Support Care Cancer. 2012;20:385-393.

5. Woerdenbag HJ, Moskal TA, Pras $\mathrm{N}$, et al., Cytotoxicity of artemisinin-related endoperoxides to Ehrlich ascites tumor cells. $J$ Nat Prod. 1993;56(6):849-856.

6. Reungpatthanaphong $\mathrm{P}$, and Mankhetkorn S. Modulation of multidrug resistance by artemisinin, artesunate and dihydroartemisinin in K562/adr and GLC4/adr resistant cell lines. Biol Pharma Bull. 2002; 25(12):1555-1561.

7. Efferth T, Saverbrey A, Olbrich et al. Moleular modes of action of artesunate in tumor cell lines. Mol Pharmacol. 2003;64(2):382-394.

8. Crespo-Ortiz MP, and Wei MQ. Antitumor activity of artemisinin and its derivatives: From a well-known antimalarial agent to a potential anticancer drug. $J$ Biomed Biotechnol. 2012; ID 247597, 18 pages.

9. Mercer AE, Copple IM, Maggs JL, O’Neill PM, and Park BK. The role of heme and the mitochondrion in 
the chemical and molecular mechanisms of mammalian cell death induced by the artemisinin antimalarials. J Biol Chem. 2011; 283(2):987-996.

10. Das AK. Anticancer effect of antimalarial artemisinin compounds. Ann Med Health Sci Res. 2015;5(2):93102.

11. Li Z, Li Q, Wu J, Wang M, Yu J. Artemisinin and its derivatives as a repurposing anticancer agent: what else do we need to do? Molecules. 2016; 21(1331):14 pages.

12. Efferth T, Willmar SA. Antiplasmodial and antitumor activity of arternisinin from bench to bedside. Planta Med. 2007;73:299-309.

13. Gordi T, and Lepist EI. Artemisinin derivatives: toxic for laboratory animals, safe for humans? Toxicol Lett. 2004;147(2):99-107..

14. Dondorp AM, Nosten F, Yi P, Das D, Phyo AP, Tarning J, Lwin KM, Ariey F, Hanpithakpong W, Lee SJ, Ringwald P, Silamut K. Artemisinin resistance in Plasmodium falciparum malaria. $N$ Eng $J$ Med. 2009;361(5):455-467.

15. Medhi B, Patyar S, Rao RS, DS Prasad Byrav, Prakash A. Pharmacokinetic and toxicological profile of artemisinin compounds: An update. Pharmacology. 2009;84(6):323-332.

16. Li Q, Weina PJ, and Milhous WK. Pharmacokinetic and pharmacodynamics profiles of rapid-acting artemisinins in the antimalarial therapy. Cur Drug Ther. 2007;2(3):210-223.

17. Kheiri-Manjili HR, Malvandic H, Mousavi MS, Attari $\mathrm{E}$ and Danafard $\mathrm{H}$. In vitro and in vivo delivery of artemisinin loaded PCL-PEG-PCL micelles and its pharmacokinetic study. Artif cells nanomed biotechnol. 2018;46(5):926-936.

18. Kheiri-Manjili1 HR, Malvandi H, Mousavi MS, Danafar H. Preparation and physicochemical characterization of biodegradable mPEG-PCL coreShell micelles for delivery of artemisinin. Pharma Sci. 2016, 22, 234-243.

19. Gharib A, Faezizadeh Z, Mesbah-Namin SAR and Saravani R. Preparation, characterization and in vitro efficacy of magnetic nanoliposomes containing the artemisinin and transferrin. DARU.2014;22(1):44-5.

20. Chen Y, Lin X, Park H, Greever R. Study of artemisinin nanocapsules as anticancer drug delivery systems. Nanomedicine. 2009;5(3):316-322.

21. Dadgar N, Norouzian D, Chiani M, EbrahimiShamabadi H, Mehrabi SMR, Farhanghi A and Akbarzadeh A. Effect of artemisinin liposome and artemisinin liposome polyethylene glycol on MCF-7 cell line. Int $\mathrm{j}$ Life Sci Biotechnol Pharm Res. 2013;2(1):349-355.

22. Letchmanan K, Shen SC, Ng WK, and Tan RBH. Enhanced dissolution and stability of artemisinin by nano-confinementin ordered mesoporous SBA-15 particles. J Microencapsul.2015;32(4):390-400.

23. Emami J, Rezazadeh M, Sadeghi H, and Khadivar KH. Development and optimization of transferrinconjugated nanostructured lipid carriers for brain delivery of paclitaxel using Box-Behnken design. Pharm Dev Technol. 2017; 22(3):370-382.

24. Gupta Y, Jain A, Jain S. Transferrin-conjugated solid lipid nanoparticles for enhanced delivery of quinine dihydrochlorideto the brain. $J$ Pharm Pharmacol. 2007;59:935-940.

25. Kuo YC, Lin PI, Wang CC. Targeting nevirapine delivery across human brain microvascular endothelial cells using transferrin-grafted poly(lactide-co-glycolide) nanoparticles. Nanomedicine. 2011;6:1011-1026.

26. Prades R, Guerrero S, Araya E, et al. Delivery of gold nanoparticles to the brain by conjugation with a peptide that recognizes the transferrin receptor. Biomaterials. 2012;33:7194-7205.

27. Ulbrich K, Hekmatara T, Herbert E, Kreuter J. Transferrin- and transferrin-receptor-antibodymodified nanoparticles enable drug delivery across the blood-brain barrier. Eur J Pharm Biopharm. 2009;71:251-256.

28. Yan F, Wang Y, He S, et al. Transferrin-conjugated, fluorescein- loaded magnetic nanoparticles for targeted delivery across the blood-brain barrier. $J$ Mater Sci Mater Med. 2013;24:2371-2379.

29. Patel M, Souto EB, Singh KK. Advances in brain drug targeting and delivery: limitations and challenges of solid lipid nanoparticles. Expert opin drug deliv. 2013;10(7):889-905.

30. Selvamuthukumar S, Velmurugan R. Nanostructured lipid carriers: a potential drug carrier for cancer chemotherapy. Lipids Health Dis. 2012;11:159-167.

31. Gao H, Yang Z, Zhang S, Cao S, Shen S, Pang Z, Jiang $X$. Ligand modified nanoparticles increases cell uptake, alters endocytosis and elevates glioma distribution and internalization. Sci Rep. 2013;3:2534-2539.

32. Chen HL, Wang KT, Pu QS, Chen XG, Hu ZD. Online conversion and determination of artemisinin using a flow-injection capillary electrophoresis system. Electrophoresis. 2002; 23(17):2865-2871.

33. Hao J, Fang X, Zhou Y, Wang J, Guo F, Li F, et al. Development and optimization of solid lipid nanoparticle formulation for ophthalmic delivery of chloramphenicol using a Box-Behnken design. Int $\mathbf{J}$ Nanomedicine. 2011;6:683-692.

34. Schubert M and Müller-Goymann C. Solvent injection as a new approach for manufacturing lipid nanoparticles: evaluation of the method and process parameters. Eur J Pharm Biopharm. 2003;55(1):12531.

35. Jafari SM, He Y, Bhandari B. Nano-emulsion production by sonication and microfluidization: a comparison. Int J Food Prop. 2006;9(3):475-485.

36. Hu FQ, Jiang SP, Du YZ, Yuan H, Ye YQ, Zeng S. Preparation and characterization of stearic acid nanostructured lipid carriers by solvent diffusion method in an aqueous system. Colloids Surf B Biointerfaces. 2005;45(3):167-173. 
37. Azhar L, Bahari Sh, Hamishehkar H. The impact of variables on particle size of solid lipid nanoparticles and nanostructured lipid carriers; A comparative iterature review. Adv Pharm Bull. 2016;6(2):143-151.

38. Roland I, Piel G, Delattre L, Evrard B. Systematic characterization of oil-in-water emulsions for formulation design. Int J Pharm. 2003;263(1-2):8594.

39. Sharma S, Shukla P, Misra A, Mishra PR. Interfacial and colloidal properties of emulsified systems: Pharmaceutical and biological perspective, In Ohshima H, Makino K, Editors. Colloid and interface science in pharmaceutical research and development. Amsterdam, Elsevier, 2014. p. 149172.

40. Souto E, Wissing S, Barbosa C, Müller R. Development of a controlled release formulation based on SLN and NLC for topical clotrimazole delivery. Int J Pharm. 2004;278(1):71-77.

41. Bunjes H, Westesen K, Koch MH. Crystallization tendency and polymorphic transitions in triglyceride nanoparticles. Int J Pharm. 1996;129(1-2):159-173.

42. Liu D, Liu Z, Wang L, Zhang C, Zhang N. Nanostructured lipid carriers as novel carrier for parenteral delivery of docetaxel. Colloids Surf B Biointerfaces. 2011;85(2):262-269.

43. Emami J, Rezazadeh M, Sadeghi H, Khadivar K. Development and optimization of transferrinconjugated nanostructured lipid carriers for brain delivery of paclitaxel using Box-Behnken design. Pharm Dev Technol. 2017;22(3):370-382.

44. Emami J, Rezazadeh M, Varshosaz J. Formulation of LDL targeted nanostructured lipid carriers loaded with paclitaxel: a detailed study of preparation, freeze drying condition, and in vitro cytotoxicity. $J$ Nanomat. 2012; Article ID: 358782, 10 pages.

45. Shieh HS, Hoard LG, Nordman CE. Crystal structure of anhydrous cholesterol. Nature. 1977;267:287-289.

46. Shah M, Pathak K. Development and statistical optimization of solid lipid nanoparticles of simvastatin by using 23 full-factorial design. AAPS PharmSciTech. 2010;11(2):489-496.

47. Caffo M, Raudino G, Caruso G. Nanotechnology and brain tumors drug delivery. Recent Pat Nanomed. 2013;3(1):26-36.

48. Khajavinia A, Varshosaz J, Dehkordi AJ. Targeting etoposide to acute myelogenous leukaemia cells using nanostructured lipid carriers coated with transferrin. Nanotechnology. 2012;23(40):405101.

49. Shen J, Sun M, Ping Q, Ying Z, Liu W. Incorporation of liquid lipid in lipid nanoparticles for ocular drug delivery enhancement. Nanotechnology. 2010;21(2):025101.

50. Varshosaz J, Eskandari S, Tabakhian M. Production and optimization of valproic acid nanostructured lipid carriers by the Taguchi design. Pharm Dev Technol. 2010;15(1):89-96.

51. Rahman HS, Rasedee A, How CW, Abdul AB, Zeenathul NA, Othman HH, et al. Zerumbone-loaded nanostructured lipid carriers: preparation, characterization, and antileukemic effect. Int $\mathbf{J}$ Nanomedicine. 2013;8:2769.

52. Jain SK, Chaurasiya A, Gupta Y, Jain A, Dagur P, Joshi B, et al. Development and characterization of 5FU bearing ferritin appended solid lipid nanoparticles for tumour targeting. J Microencap. 2008;25(5):289297.

53. Soni V, Kohli D, Jain S. Transferrin-conjugated liposomal system for improved delivery of 5fluorouracil to brain. J Drug Target. 2008;16(1):7378.

54. Yan F, Wang Y, He S, Ku S, Gu W, Ye L. Transferrin-conjugated, fluorescein-loaded magnetic nanoparticles for targeted delivery across the bloodbrain barrier. $J$ Mater Sci Mater Med. 2013;24(10):2371-2379.

55. Zhang $\mathrm{P}, \mathrm{Hu}$ L, Yin Q, Zhang Z, Feng L, Li Y. Transferrin-conjugated polyphosphoester hybrid micelle loading paclitaxel for brain-targeting delivery: synthesis, preparation and in vivo evaluation. J Control Release. 2012;159(3):429-434.

56. Cui Y, Xu Q, Chow PK-H, Wang D, Wang C-H. Transferrin-conjugated magnetic silica PLGA nanoparticles loaded with doxorubicin and paclitaxel for brain glioma treatment. Biomaterials. 2013;34(33):8511-8520.

57. Efferth T, Benakis A, Romero MR, Tomicic M, Rauh $\mathrm{R}$, Steinbach D, et al. Enhancement of cytotoxicity of artemisinins toward cancer cells by ferrous iron. Free Radic Biol Med. 2004;37(7):998-1009.

58. Sadava D, Phillips T, Lin C, Kane SE. Transferrin overcomes drug resistance to artemisinin in human small-cell lung carcinoma cells. Cancer lett. 2002;179(2):151-156. 